\title{
Prediction of optimal CPAP pressure in patients with OSAS in Turkish population
}

\author{
Hakan Celikhisar, Gulay Dasdemir Ilkhan \\ İzmir University of Economics Turkey \\ Okmeydanı Training and Research Hospital Turkey
}

\begin{abstract}
The most effective therapy defined for the patients with obstructive sleep apnea syndrome (OSAS) is the continuous positive airway pressure (CPAP). In this study, we aimed to construct a CPAP prediction formula in Turkish population in order to decrease the requirements for polysomnography (PSG) laboratories. The demographic features, age, gender, weight and height of the participants were recorded at the first visit, together with the neck, waist and hip circumferences. Epworth Sleepiness Scale (ESS) was used to evaluate the levels of daytime sleepiness. All patients underwent at least two PSG studies. In a total of 269 patients with a mean age of $53.42 \pm 13.32$ years were included in the study. In step-wise multiple regression analysis; BMI, AHI, ARI, and neck circumference were the independent predictors of CPAP. A new formula was developed using these values: CPAP pred: (BMI X 0.138) + (AHI X 0.044) + (ARI X 0.056) +(NECK X 0.151) -6.180. The mean CPAP was 7.70 \pm 2.48 and the mean CPAP pred was $7.71 \pm 1.53$. When the mean CPAP and CPAP pred values were compared, there was not a significant difference with a $p$ value of 0.846 . There was a significant correlation between CPAP and CPAP pred values (p:0.001 and r:0.613). We determined that, predicting CPAP with high accuracy may be possible with formulations. These formulations are important in order to reduce the requirements for repeated PSG. Further, larger, prospective studies are required to increase the accuracy of CPAP predicting formulas.
\end{abstract}

Key words: Obstructive sleep apnea syndrome,

\section{Introduction}

Obstructive sleep apnea syndrome (OSAS) is characterized by repeated obstruction of the upper airways during sleeping, which results in the blockade of breathing and excessive daytime sleepiness. OSAS is a public health problem with many social, legal, and economic impacts $(1,2)$. The most effective therapy defined for the patients with OSAS is the continuous positive airway pressure (CPAP) $(3,4)$. The gold standard for the determination of CPAP is the conventional manual titration under attended polysomnography (PSG). However, this is time-consuming and causing long lists for PSG laboratories since PSG is not available in all medical centers.

In previous literature, there are some formulas suggested in different ethnic populations, to predict CPAP without repeated PSG séances. The most commonly used parameters in those formulas were body mass index (BMI), neck circumference (NC), continuous positive airway pressure, predicted value and apnea-hipopnea-index (AHI). In previous literature, it was clearly defined that, using a predictive formula derived from the same ethnic group is more appropriate than using one based on a different ethnic group (5-7).

To the best of our knowledge, the data regarding the predicting CPAP with preceding PSG findings and anthropometric measures is limited in Turkish population in previous literature.

In this study, we aimed to construct a CPAP prediction formula in Turkish population in order to decrease the requirements for PSG laboratories, in our developing country.

\section{Material and Method}

In a total of 269 patients with OSAS, diagnosed and treated in Esrefpasa Municipality Hospital, sleep laboratory between January 2016 and January 2019 were included in the study.

The study was approved by the local ethics 
committee. Informed consent was obtained from all participants. The demographic features, age, gender, weight and height of the participants were recorded at the first visit, together with the neck, waist and hip circumferences. Body mass index (BMI) was calculated as weight /(height $)^{2}$. Epworth Sleepiness Scale (ESS) was used to evaluate levels of daytime sleepiness (8). All subjects having an apneahypopnea index (AHI) value $>5$ events/h were diagnosed with OSAS at an initial overnight diagnostic polysomnography were included in the study.

All patients underwent at least two PSG studies using the Alice4 system (Philips Respironics GK). The first was to diagnose OSAS and the second was to determine the optimal CPAP. During PSG, biological variables were incessantly recorded using electrocardiography, electroencephalography, submental and anterior tibial electromyography and electrooculography. Air flow was measured by a nasal cannula with a pressure transducer. Chest and abdominal movements were monitored. Arterial oxygen saturation was analyzed continuously by pulse oximetry. Body position was assessed by a monitor and a sensor.

During PSG, sleep-related respiratory events and arousals were scored according to the American Academy of Sleep Medicine Manual for Scoring Sleep and Associated Events (9). The oxygen desaturation index (ODI) was defined as the number of desaturation $>3 \%$ per hour of sleep. Obstructive apnea was defined as the absence of airflow for longer than 10 seconds; obstructive hypopnea was defined as at least $50 \%$ reduction in airflow for longer than 10 seconds, and was associated with an electroencephalographic arousal or desaturation of $>3 \%$. The apnea-hypopnea index (AHI) was calculated as the number of apnea and hypopnea events per hour of sleep. AHI score between 5 and 14 was defined as mild, between 15 and 29 was considered as moderate and $\mathrm{AHI} \geq 30$ was considered as severe OSAS.

Auto-titrating CPAP was used in the sleep laboratory within a week after the diagnostic study to get a fixed CPAP pressure value.

\section{Statistical Analyses}

Statistical analyses were performed using SPSS version 21.0 (SPSS Inc., Chicago, IL, USA). All data were presented as mean \pm standard deviation (SD) for continuous variables and as frequencies
(\%) for categorical variables. Pearson correlations were performed between titrated CPAP and sleep architecture measures as well as the demographic and anthropometric data. Stepwise multiple regression analysis was performed to define the association of these parameters with CPAP. A new formula was adopted to predict the CPAP. These two CPAP values, predicted and titrated, were compared with paired samples $t$ test and their correlation was analyzed with Pearson correlation analysis. Statistical significance was set at $p<0.05$.

\section{Results}

In a total of 269 patients with a mean age of 53.42 \pm 13.32 years were included in the study. Among participants $115(42.8 \%)$ were female and 154 $(57.2 \%)$ were male. Baseline characteristics of the study participants are summarized in Table 1.

Table I. Baseline Characteristics of Study Participants

\begin{tabular}{|l|l|l|}
\hline & Mean \pm SD & Range \\
\hline Age (years) & $53.42 \pm 13.32$ & $33.00-85.00$ \\
\hline $\begin{array}{l}\text { Body Mass Index } \\
\left(\mathrm{kg} / \mathrm{m}^{2}\right)\end{array}$ & $32.94 \pm 3.49$ & $23.10-41.00$ \\
\hline $\begin{array}{l}\text { Epworth Sleepiness } \\
\text { Score }\end{array}$ & $7.38 \pm 5.72$ & $0.00-20.00$ \\
\hline $\begin{array}{l}\text { Neck } \\
\text { circumference (cm) }\end{array}$ & $43.05 \pm 2.46$ & $36.00-50.00$ \\
\hline $\begin{array}{l}\text { Waist } \\
\text { circumference (cm) }\end{array}$ & $110.34 \pm 7.90$ & $84.00-133.00$ \\
\hline $\begin{array}{l}\text { Hip circumference } \\
(\mathrm{cm})\end{array}$ & $112.61 \pm 7.47$ & $95.00-144.00$ \\
\hline
\end{tabular}

According to the AHI values, 62 (23\%) patients were having mild, $97(36.1 \%)$ were having moderate and 110 (40.9\%) were having severe OSAS. The main PSG findings of study participants are summarized in Table 2.

Table 2. The main polysomnography findings of study participants

\begin{tabular}{|l|l|l|}
\hline & Mean \pm SD & Range \\
\hline $\begin{array}{l}\text { Total sleep } \\
\text { time (min) }\end{array}$ & $429.94 \pm 36.96$ & $318.00-504.00$ \\
\hline
\end{tabular}


Hakan Celikhisar et. al/ Prediction of optimal CPAP pressure in patients with OSAS in Turkish population

\begin{tabular}{|lr|l|l|}
\hline $\begin{array}{l}\text { Total sleep } \\
\text { time } \\
(\%)\end{array}$ & $20.55 \pm 23.97$ & $3.10-269.00$ \\
\hline AHI $)$ & & $31.74 \pm 22.05$ & $5.00-101.70$ \\
\hline ARI & $25.88 \pm 11.92$ & $2.30-54.40$ \\
\hline $\begin{array}{l}\text { Mean SaO2 } \\
\text { during sleep }\end{array}$ & $93.31 \pm 2.48$ & $85.00-97.00$ \\
\hline $\begin{array}{l}\text { Minimum } \\
\text { SaO2 during } \\
\text { sleep }\end{array}$ & $79.66 \pm 9.63$ & $50.00-94.00$ \\
\hline ODI & $29.15 \pm 20.37$ & $2.60-90.10$ \\
\hline
\end{tabular}

In all study participants, the correlation of CPAP with demographic, anthropometric and PSG findings are analyzed. The results of correlation analysis are summarized in Table 3.

Table 3. The correlation of CPAP with demographic, anthropometric and PSG findings

\begin{tabular}{|l|l|l|}
\hline & $\begin{array}{l}\text { Correlation } \\
\text { coefficient }\end{array}$ & $\mathrm{p}$ \\
\hline BMI $\left(\mathrm{kg} / \mathrm{m}^{2}\right)$ & 0.407 & 0.0001 \\
\hline $\begin{array}{l}\text { Neck circumference } \\
(\mathrm{cm})\end{array}$ & 0.376 & 0.0001 \\
\hline $\begin{array}{l}\text { Waist } \\
\text { circumference (cm) }\end{array}$ & 0.418 & 0.0001 \\
\hline $\begin{array}{l}\text { Hip circumference } \\
(\mathrm{cm})\end{array}$ & 0.388 & 0.0001 \\
\hline Epworth score & 0.227 & 0.0001 \\
\hline ARI & 0.217 & 0.0001 \\
\hline AHI & 0.471 & 0.0001 \\
\hline Desaturation/min & 0.438 & 0.0001 \\
\hline ODI & 0.456 & 0.0001 \\
\hline
\end{tabular}

The mean CPAP was $7.70 \pm 2.48$ and the mean predicted CPAP (CPAP pred) was $7.71 \pm 1.53$. When the mean CPAP and CPAP pred values were compared, there was not a significant difference with a $\mathrm{p}$ value of 0.846 . There was a significant correlation between CPAP and CPAP pred values (p:0.001 and r:0.613). In 119 (44.2\%) patients, the formula predicted the titrated CPAP within less than $1 \mathrm{~cm}-\mathrm{H} 2 \mathrm{O}$ difference. In $193(71.7 \%)$ patients, the formula predicted the titrated CPAP within less than $2 \mathrm{~cm}-\mathrm{H} 2 \mathrm{O}$ difference. The distribution of CPAP titrated and CPAP predicted is summarized in Figure 1 and the differences between CPAP titrated and CPAP predicted is shown in Figure 2.

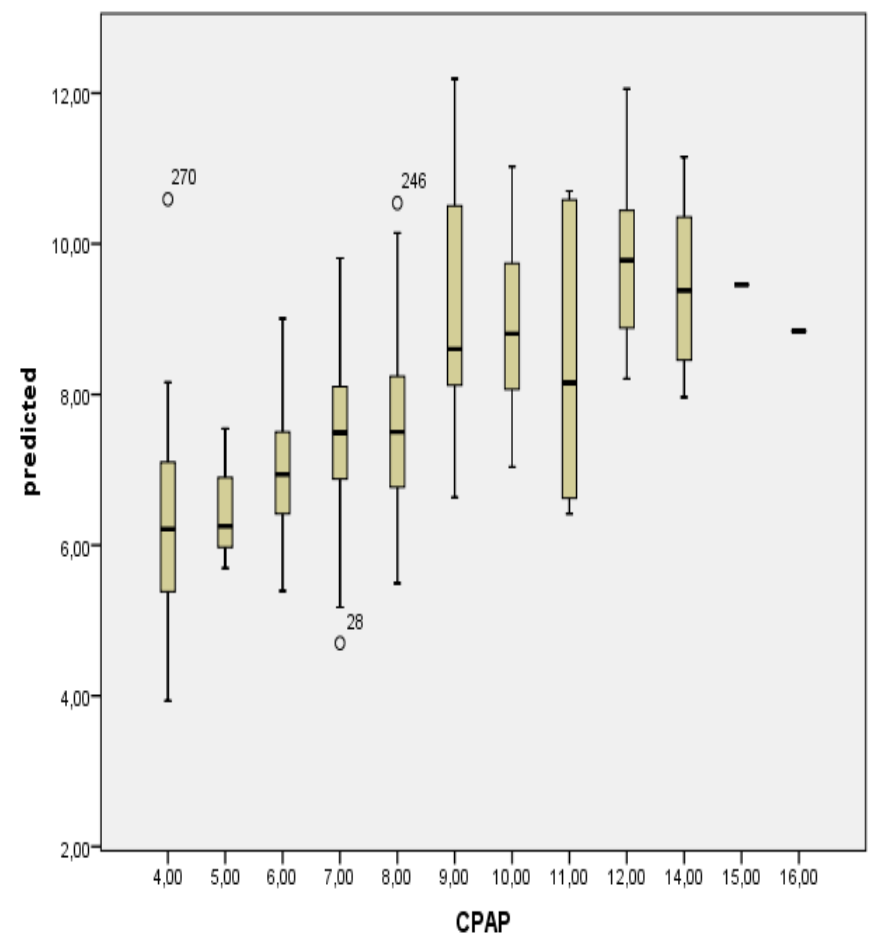

Figure I. The distribution of CPAP titrated and CPAP predicted

In step-wise multiple regression analysis including all those variables with significant correlations; BMI, AHI, ARI, and neck circumference were the independent predictors of CPAP. In that aspect, a new formula was obtained:

CPAP pred: (BMI X 0.138) + (AHI X 0.044) + $($ ARI X 0.056) +(NECK X 0.151) -6.180 


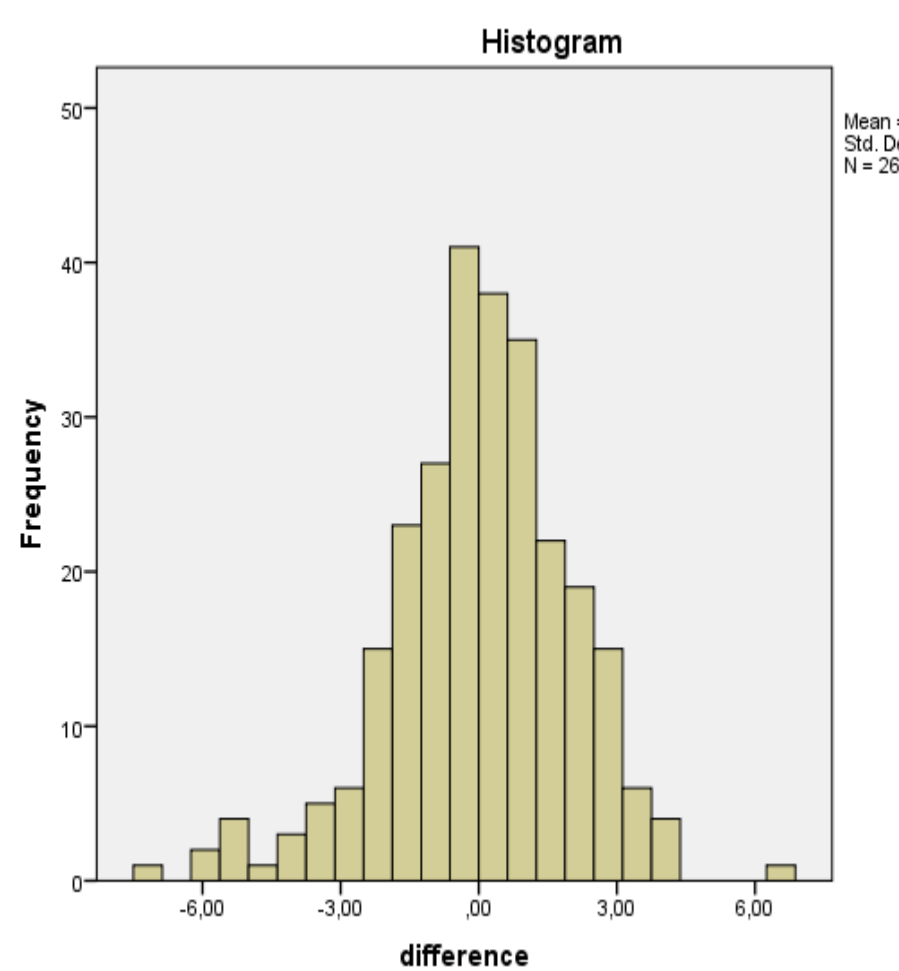

Figure 2. The distribution of the differences between CPAP titrated and CPAP predicted

\section{Discussion}

In this study, we analyzed the parameters specifically important in CPAP prediction, in the absence of titration with a second PSG; and we determined that with a formula including BMI, AHI, ARI, and neck circumference, CPAP could be predicted with a high correlation with titrated CPAP in Turkish population.

Secondary PSG requirement, for the CPAP titration in patients diagnosed with OSAS, generates some great problems such as long lists in PSG laboratories causing waste of time and money. For that reason, some alternative methods are investigated in previous literature and some formulas were suggested. Lin et al (10) reported that, in Taiwanese people with moderate to severe OSAS, a prediction model based on only AHI and BMI was accurately predicting CPAP. They also reported that, inclusion of other parameters such as neck circumference did not improve the accuracy of prediction of the formula. In Japaneese patients, Akahoshi et al (11) reported that AHI, BMI, mean $\mathrm{SaO} 2$ and a cephalometric parameter were the independent predictors of optimal CPAP. Hoffstein and Séries formulas are the most commonly used formulas for this purpose in previous literature, and both are based on BMI, neck circumference and

AHI (12,13). In a prospective study on 1,111 patients with OSAS in Greek population, Schiza et al (14) reported that both Hoffstein formula and another formula including AHI, BMI, smoking history and gender adjustment; successfully predicted the CPAP pressure. In Korean subjects with OSAS, Lee at al (15) defined a new formula based on $\mathrm{BMI}$, minimal $\mathrm{SpO} 2$, respiratory disturbance index and Epworth Sleepiness Scale for the prediction of CPAP. They reported that, this formula was somewhat better to predict optimal CPAP level in Asian subjects than the Hoffstein equation; but it did not accurately predict the prescribed CPAP level. In Turkish population we found only one study regarding the prediction of CPAP in OSAS patients. In that study, Basoglu and Tasbakan (16) defined a new formula including neck circumference and oxygen desaturation index for the prediction of CPAP and they reported that the predicted CPAP was having a significant correlation with the titrated CPAP. Cancelo et al (17) compared Hoffstein equation with another prediction formula based on the same parameters with Hoffstein; and reported that correlation of predicted formulas with titrated CPAP was not good. In a study of Roman et al (18) in 2514 male patients, Hoffstein formula was reported to underestimate CPAP pressure and in contrast Séries formula was overestimating the titrated CPAP. In a systematic review of literature for mathematical equations used to predict effective pressures for positive airway pressure (PAP) devices, BMI and mean oxygen saturation were reported to be the most heavily weighted criteria (19).

In fact, our results are consistent with the previous literature. BMI, AHI, and neck circumference are the most commonly included determinants in predicting CPAP. However, one interesting finding of this study was the role of ARI in prediction of CPAP. To the best of our knowledge, this is the first study in literature defining a CPAP prediction formula based on ARI. In children arousal index was reported to be associated with the endothelial dysfunction (20). In adults, arousal index was an independent predictive factor for the occurrence of atherosclerosis and insulin resistance $(21,22)$. In that aspect arousal index seems to be a good predictor of systemic inflammation in OSAS and we determined that, it has a significant role in predicting CPAP.

There are some limitations of the study that should be mentioned. The main limitation was that; the population was not homogenous in terms of the severity of OSAS which may alter the results. Second, we did not analyze the efficacy of the titrated CPAP values in further follow-ups. 
In conclusion, we determined that, predicting CPAP with high accuracy may be possible with formulations. These formulations are important in order to reduce the requirements for repeated PSG. Further, larger, prospective studies are required to increase the accuracy of CPAP predicting formulas in different populations.

\section{References}

1. Vasu TS, Grewal R, Doghramji K. Obstructive sleep apnea syndrome and perioperative complications: a systematic review of the literature. J Clin Sleep Med 2012;8(2):199-207.

2. Faber J, Faber C, Faber AP. Obstructive sleep apnea in adults. Dental Press J Orthod. 2019 Aug 1;24(3):99-109.

3. Kakkar RK, Berry RB. Positive airway pressure treatment for obstructive sleep apnea. Chest. 2007 Sep; 132(3):1057-72.

4. Epstein LJ, Kristo D, Strollo PJ Jr Et al. Clinical guideline for the evaluation, management and longterm care of obstructive sleep apnea in adults. J Clin Sleep Med 2009;5(3):263-76.

5. Stradling JR, Hardinge M, Paxton J, Smith DM. Relative accuracy of algorithm-based prescription of nasal CPAP in OSA. Respir Med. 2004; 98: 152-154.

6. Schiza SE, Bouloukaki I, Mermigkis C, Panaqou $\mathrm{P}$, Tzanakis $\mathrm{N}$, et al. Utility of formulas predicting the optimal nasal continuous positive airway pressure in a Greek population. Sleep Breath. 2011; 15: pp. 417-423.

7. Loredo JS, Berry C, Nelesen RA, Dimsdale JE. Prediction of continuous positive airway pressure in obstructive sleep apnea. Sleep Breath. 2007; 11: 45-51.

8. Johns MW. A new method for measuring daytime sleepiness: The Epworth sleepiness scale. Sleep, 1991; 14: 540-545.

9. Iber C, Ancoli-Israel S, Chesson A, Quan SF. The AASM manual for the scoring of sleep and associated events: rules, terminology and technical specifications, 1st ed. American Academy of Sleep Medicine, Westchester, 2007.
10. Lin IF, Chuang ML, Liao YF, Chen NH, Li HY.Predicting effective continuous positive airway pressure in Taiwanese patients with obstructive sleep apnea syndrome. J Formos Med Assoc. 2003 Apr;102(4):215-21.

11. Akahoshi T, Akashiba T, Kawahara S, Uematsu A, Nagaoka K, Kiyofuji K, Okamoto N, Hattori T, Takahashi N, Hashimoto S. Predicting optimal continuous positive airway pressure in Japanese patients with obstructive sleep apnoea syndrome. Respirology. 2009 Mar;14(2):245-50.

12. Miljeteig H, Hoffstein V. Determinants of continuous positive airway pressure level for treatment of obstructive sleep apnea. Am Rev Respir Dis 1993;147(6 Pt 1):1526-1530. 8.

13. Series F. Accuracy of an unattended home CPAP titration in the treatment of obstructive sleep apnea. Am J Respir Crit Care Med 2000;162(1):94-97.

14. Schiza SE, Bouloukaki I, Mermigkis C, Panagou P, Tzanakis N, Moniaki V, Tzortzaki E, Siafakas NM.Utility of formulas predicting the optimal nasal continuous positive airway pressure in a Greek population. Sleep Breath. 2011 Sep;15(3):417-23.

15. Lee GH, Kim MJ, Lee EM, Kim CS, Lee SA. Prediction of optimal CPAP pressure and validation of an equation for Asian patients with obstructive sleep apnea. Respir Care. 2013 May;58(5):810-5.

16. Basoglu OK, Tasbakan MS. Determination of new prediction formula for nasal continuous positive airway pressure in Turkish patients with obstructive sleep apnea syndrome. Sleep Breath. 2012 Dec;16(4):1121-7.

17. Cancelo L, Hernandez V, Bravo D, Martinez C, Egea C, Duran J. CPAP titration: correlation between 2 different equations and autocpap. Sleep Medicine. 2013: 14 (supp 1); e87. 
18. Román B, Rosillo EM, Hernández L, Zamora L, Carlos B. Optimal pressure determination for CPAP in the treatment of obstructive sleep apnea syndrome (OSAS). Comparison of prediction equations and autoCPAP titration. European Respiratory Journal. 2013; 42: P3580.

19. Camacho M, Riaz M, Tahoori A, Certal V, Kushida CA. Mathematical Equations to Predict Positive Airway Pressures for Obstructive Sleep Apnea: A Systematic Review. Sleep Disord. 2015;2015:293868.

20. Zhang F, Wu Y, Feng G, Ni X, Xu Z, Gozal D. Polysomnographic correlates of endothelial function in children with obstructive sleep apnea. Sleep Med. 2018 Dec;52:45-50.

21. Suzuki M, Shimamoto K, Sekiguchi H, Harada T, Satoya N, Inoue Y, Yamaguchi K, Kawana M. Arousal index as a marker of carotid artery atherosclerosis in patients with obstructive sleep apnea syndrome.Sleep Breath. 2019 Mar;23(1):87-94.

22. Bulcun E. Ekici M. Ekici A. Disorders of glucose metabolism and insulin resistance in patients with obstructive sleep apnoea syndrome. Int. J. Clin. Pract. 2012;66(1):9197. 